\title{
NÃO QUERO MAIS NEGAR MINHA ALMA*
}

\author{
I Can no Longer Deny my Soul
}

\section{Luciany Aparecida Alves Santos}

Universidade da Integração Internacional da Lusofonia Afro-Brasileira (Unilab/Malês). São Francisco do Conde, BA, Brasil

E-mail: luciany.aaparecida@gmail.com

\section{RESUMO}

Luiz Maurício Azevedo é autor de Estética e raça: ensaios sobre a literatura negra, lançado em 2021. O livro é composto por um prólogo e dezesseis requintados ensaios que, de modo pontual e assertivo, tecem uma trama narrativa sobre a estética da literatura negra.

PALAVRAS-CHAVE: Teoria literária, ensaio, literatura negra.

\section{ABSTRACT}

Luíz Maurício Azevedo is the author of Estética e raça: ensaios sobre a literatura negra (Aesthetics and Race: Essays on Black Literature, free translation), released in 2021. The book consists of a prologue and sixteen exquisite essays, which in an accurate and assertive manner constructs a narrative plot about the aesthetics of black literature.

KEYWORDS: Literary theory, essay, black literature.

EDITORES:

Regina Zilberman

Gerson Roberto Neumann

SUBMETIDO: 25.03 .2021

ACEITO: 12.04 .2021

\section{COMO CITAR:}

SANTOS, Luciany Aparecida Alves. Não quero mais negar minha alma. Revista Brasileira de Literatura Comparada, v. 23 , n. 43 , p. 140-145, mai.ago., 2021. doi: https:// doi.org/10.1590/2596$304 \times 20212343$ laas http:// www.scielo.br/rblc https://revista.abralic.org.br
"Nós temos uma alma. E ela não está à venda" (AZEVEDO, 2021,p. 10). Essas são palavras do escritor Luiz Maurício Azevedo na abertura do livro Estética e raça: ensaios sobre a literatura negra. Novíssima publicação do campo da crítica e teoria literária que está dando as caras no cenário intelectual brasileiro. E se esse texto dá as caras, eu quero beijá-lo. Essa expressão é uma referência a capa do jornal do Movimento Negro Unificado (MNU) de 1991 que trazia a foto de um homem negro e uma mulher negra se beijando e a frase "reaja a violência racial/beije sua preta em praça pública".

"Beije sua preta em praça pública”, verso do poeta Orí/Lande Onawale, não é um poema sobre a sexualização do corpo negro, ou a excitação folclórica que, numa perspectiva racista, pode perpassar o campo semântico de qualquer afirmativa que traga junto as palavras: cara, beijo, negro, negra. O ânimo aqui, e na referida capa, é de afirmação intelectual e política. O beijar uma cara negra em lugar de exposição civil é uma marcação de posicionamento teórico. É uma afirmação social antirracista. Uma escolha positiva de afirmar amor-vida a um corpo que, numa estrutura racista, tem na rua, no encontro social seu lugar de quase-morte.

\footnotetext{
* Resenha de: AZEVEDO, Luiz Maurício. Estética e raça: ensaios sobre a literatura negra. Porto Alegre: Sulina, 2021. 140 p.
} 
Esse posicionamento estético-político é um caminho de análise nesse livro, por exemplo, nos ensaios, nas declarações de amor que o autor faz a Ralph Ellison, destacando sua obra pontual e necessária ao campo literário americano que queira se afirmar antirracista; a Toni Morrison e os verdadeiros elogios à relação brilhante que essa estabelece e costura entre suas obras literárias e seus ensaios críticos; e a Jeferson Tenório, escritor que agora seafirmou no cenário nacional da literatura brasileira, mas que já vinha sendo apontado por Azevedo como uma grande referência em tantas anteriores resenhas feitas pelo crítico. E na orelha, na declaração de amor que o autor faz à poeta Fernanda Bastos, sua esposa, mulher negra, escritora e editora que também tem sido pontual na consolidação de um pulsante cenário da literatura negra brasileira.

Destaco essas declarações de amor apresentadas no brilhante e inspirador livro de crítica e teoria de Luiz Maurício Azevedo, porque não quero mais negar minha alma. Como escreve bell hooks em Ensinando a transgredir, vivemos numa "sociedade que gostaria de nos fazer crer que não há dignidade na experiência da paixão" (HOOKS, 2017, p. 233). E nesse contexto lê-se o pensamento-intelectual como uma separação entre: corpo, mente, espírito. Se lemos a partir dessa conjuntura de análise a forjada intelectualidade brasileira, como veio se sustentando nesse dualismo metafísico ocidental, entendemos que "chamar atenção para o corpo é trair um legado de repressão" (HOOKS, 2017, p. 253). É nessa linha teórica que o livro Estética e raça se sustenta como um beijo na face de um corpo negro em praça pública. E esse movimento é uma ação estética, política que diz respeito à coragem.

Do mesmo modo, também é um exercício antirracista ler a oração "temos uma alma" como um deslocamento epistêmico, proposto por Luiz Maurício Azevedo, que retoma uma das argumentações dos "começos" da história do Brasil. E faço referência a justificativa do cristianismo, "os negros não tem alma”, para defender o escravismo africano no processo das colonizações europeias na América. Postura já reconhecida pela Igreja Católica que, na figura do papa João Paulo II, pediu "perdão" a negros e índios pela "conivência" da instituição com o escravismo no período da colonização.

Luiz Maurício Azevedo, ao afirmar "temos uma alma”, risca um posicionamento público afetivo contra "os começos". E aqui escrevo começos entre aspas para referenciar o título do prólogo que Azevedo nomeia de "Sobre os começos deste livro". Esse começo do livro Estética e raça é tão pontual e assertivo quanto os ensaios que o seguem. Como numa costura, Azevedo escreve seu texto sobre estética da literatura negra trazendo referências literárias, acrescidas de elementos biográficos que funcionam no livro como pinceladas conceituais que apontam para questões do campo da história, sociologia e antropologia. Esses diálogos não diminuem as análises estéticas de sua obra, mas solidificam o livro Estética e raça numa estrutura de análise que é mesmo o trabalho que deve realizar uma crítica literária.

Como disse Rosangela Sarteschi no texto de orelha do Estética e raça, "ao tocar em questões candentes como identidade negra na escrita literária, Azevedo não pretende fazer do conceito o único foco da sua intervenção crítica". E é indispensável que assumamos que fazer essas ressalvas diz mais da expectativa do campo enviesado que livros como esse podem cair, pensando o campo intelectual brasileiro como um terreno ainda racista, do que da estrutura do livro em si. É possível afirmar que Estética e raça possui como característica, e quiçá seja essa a principal, a honestidade intelectual com a qual se posiciona de modo crítico-teórico diante da literatura negra. Um texto de crítica literária para ser saudável precisa ter a presença de um leitor corajoso e é esse o lugar de posição intelectual do novíssimo livro do Luiz Maurício Azevedo: o lugar de uma leitura honesta e corajosa. 
Estética e raça é um livro de crítica literária atenta à escrita do texto. Sentimos o leitor, tendo como posição de análise a leitura. A escrita do texto literário negro é o lugar de partida e o principal ponto de chegada. E isso que parece óbvio nem sempre é quando o assunto é crítica literária que se dedique a analisar e discutir um texto negro, pois a saudade da escravatura, cria do pensamento da mestiçagem de Gilberto Freyre, por exemplo, pode desencadear uma crítica literária que produz uma leitura da literatura negra como exótica; ou a posição da culpa que não lerá o texto em si, mas que apenas tecerá elogios às capas.

Estética e raça é uma contribuição que revigora esse campo de análise quando apresenta apontamentos críticos que questionam de modo saudável e sincero a ainda "imposição de um sujeito universal" (CARNEIRO, 2019). E nessa perspectiva de leitura, e estabelecendo diálogo com o pensamento de Sueli Carneiro (2019), destaco que ler o negro na "miscigenada" teoria da "diversidade" do discurso da nação pode ser ainda repetir o "jeito especial" de ver o branco, e toda a estética que o concerne, como a "regra" civilizatória que pautará todas as produções literárias nacionais. Nesse desenho, ainda dialogando com as teorias de Carneiro, o corpo negro e o indígena, e as estéticas que os concernem, são lidas naquelas já "tradicionais", racistas e cansativas "pinceladas culturais exóticas”. O que Estética e raça nos revela é um lugar de uma crítica acesa que traz saudável oxigenação para o cenário da crítica literária brasileira.

Por isso, destaco que a manutenção de uma cena da crítica literária que não se exercite para escapar dessa linha simplista e eurodescendente é contributária para um cenário político nacional que privilegia a despolitização. E que criminaliza o intelectualismo negro. Posturas que, consequentemente, corroboram com esse nosso afundar contemporâneo contrademocrático. Assim, reafirmo que Estética e raça provoca saudável oxigenação no cenário da crítica literária brasileira.

Estética e raça: ensaios sobre a literatura negra é uma coletânea, que apresenta um prólogo e dezesseis textos, que o autor vem colecionando ao longo de uma robusta prática de produção de crítica literária. Luiz Maurício Azevedo nasceu em 1980, é doutor em Teoria e História Literária pela Universidade Estadual de Campinas (Unicamp), com período-sanduíche na Rutgers University, Newark-NJ (EUA), e agora realiza pós-doutorado na Universidade de São Paulo (USP). E há somados anos vem dedicando-se ao estudo, análise, escrita e publicação de críticas literárias. Seus textos são como pequenas doses antiofídicas que podem produzir anticorpos antirracistas naquelas pessoas que os lerem. E que essa reação produza leituras atentas e não o envenenamento, ou nas palavras do autor, "a derrota da crítica" (AZEVEDO, 2021, p. 35). Ainda citando Azevedo, esse envenenamento seria aquele "ponto que já não é possível separar a crítica ao cânone brasileiro de um mero espetáculo autoindulgente, cujo sentido primeiro é o de reforçar uma ideia vaga de redenção moral por meio da atividade intelectual” (AZEVEDO, 2021, p. 37). Estética e raça escapa desse marasmo e nos oferece uma crítica literária renovadora.

Assim, ao longo dos dezesseis ensaios do Estética e raça, somos pessoas convidadas a trilhar caminhos de revisão da historiografia da literatura brasileira, a revisão dos caminhos de formação da própria crítica literária nacional, a partir de uma posição a contrapelo em que a grande brincadeira não é apenas a desleitura, mas ainda, e principalmente, a leitura. Quando o autor afirma "neste país a memória oficial serve para proteger os brancos da verdade histórica de seus crimes" (AZEVEDO, 2021, p. 24), ele está nos impelindo a pensar onde e como a historiografia e/ou a crítica literária beneficiaram 
essa estrutura. E pontuando que esse olhar não encere um fim, mas que ele seja um começo de ânimo para buscar ainda novas e necessárias referências.

Estética e raça faz isso, apresenta atenta leitura de textos da literatura negra contemporânea, expondo-os a um dedicado lugar de análise. E, copiando Azevedo, "se porventura não resistirem ao batismo de fogo de uma crítica, já terão cumprido o trajeto ordinário das obras, e poderão, de forma natural, sumir sob a ação do tempo, da apropriação ou mesmo do silêncio de certas audiências" (AZEVEDO, 2021, p. 45). Quer dizer, Estética e raça nos ensina que a crítica não precisa ser racista para ser assertiva. E que pode ser antirracista cumprindo esse simples papel que é ler com olhos atentos e ampliadores.

O primeiro e o segundo ensaios do livro nos orientam nessa construção teórica ao realizar uma revisão bibliográfica de referências que alimentaram tanto a historiografia quanto a crítica nessa estrutura de reprodução de leituras enviesadas pelo racismo ou pelos silenciamentos. A partir do terceiro ensaio, "O livro invisível”, temos o começo das exemplificações de como seguir esse caminho teórico, proposto pelo autor, mas sem cair nos "consensos fáceis" (AZEVEDO, 2021, p. 69). Ralph Ellison e seu livro Homem invisível talvez sejam o ponto de partida simbólica dessa engrenagem que Luiz Maurício Azevedo vai tramando para uma mais visível produção da crítica de uma literatura negra.

E assim vamos passar por Colson Whitehead, o prêmio Pulitizer, Paraty, Os meninos do reformatório, a fragilidade da crítica nacional em alimentar "o mero exercício do ver-se no espelho" (AZEVEDO, 2021, p. 72); Toni Morrison e a relação entre criação e crítica literária, e os preços a pagar por posturas que uma "reflexão intelectualmente corajosa impõe" (AZEVEDO, 2021, p. 82). Nessa sequência, o livro Estética e raça nos apresenta uma refinada discussão sobre enfrentamento da tradição crítica de autores. A coragem necessária ao pronunciar-se, e essa pronúncia diz da escrita, a necessidade de produção de uma literatura que de fato crie. E que essa criação possa saudavelmente romper com o que uma crítica literária defina como lugar de valia, principalmente, se essa crítica alimenta determinados vícios.

Construção intelectual que é genial no sexto ensaio "A origem do nosso nome" e que ganha ainda mais complexidade e beleza no sétimo ensaio, "A pedagogia invisível da morte" quando o autor aproxima essa sugerida construção de um campo de liberdade intelectual à possibilidade da liberdade do sonho de uma criança negra na estrutura escolar brasileira e, consequentemente, a depressão e queda desse sonho com o encontro com o racismo. Aqui vale a citação completa:

sonho com um mundo em que a morte não seja a única operação de renovação possível na vida cultural brasileira. Acredito na coragem antropológica, naquela feita com verdade, técnica, erudição e rancor. É uma crença importante para quem pertence à classe dos desclassificados, para quem sabe o peso do algodão (AZEVEDO, 2021, p. 93-94).

Estética e raça é um livro de ensaios sobre literatura negra que traz alguns textos do autor já publicados individualmente em jornais e revistas, mas que nesse volume somam uma unidade de leitura tão complexa quanto linda. É encantador notar como os ensaios vão se desdobrando, ao passo que vão retomando as discussões teóricas apontadas nos dois primeiros textos do livro. Como exemplo, as problematizações levantadas a partir das citações do texto Tradition and the individual talent, do T. S. Eliot, que está no segundo ensaio "Ideologias literárias da cor na reconfiguração do cânone brasileiro" e que são compreensões fundantes para o entendimento das discussões sequenciais. 
A partir do ensaio oito, “Onde estão os negros?”, começamos a ler, de modo mais detido, exemplos de uma literatura negra brasileira contemporânea. Que são exemplos: Jeferson Tenório, Conceição Evaristo, Cidinha da Silva, Ronald Augusto, Priscila Pasko. Autorias contemporâneas que ganham, no Estética e raça, textos deliciosos e afiados sobre alguns de seus livros. Ensaios críticos que abrem, ascendem e aquietam anseios nos olhos e nas vontades daquelas pessoas que ainda não conhecem essas referências. Luiz Maurício Azevedo escreve sobre o texto contemporâneo, ponderando conclusões para aquele que acredita tê-las e incendiando desejos naqueles que podem não tê-los. Em gracejo, digo que esse é um livro perigoso. Aqui escrevo perigo como um risco intelectual valente e sempre contemporâneo. É assim que, sem deixar de ser individual e crítico-teórico em cada ensaio, Estética e raça apresenta uma bela estrutura de unidade. E todos os dezesseis ensaios comprovam isso.

Jeferson Tenório é sem dúvida o autor contemporâneo da predileção do crítico, ou, ao menos, é o que melhor comprova suas análises assertivas sobre projeções no cenário da literatura nacional. Estética e raça é um livro irônico, divertido e sobretudo emocionante, como deve ser mesmo um livro de crítica literária: vivo. Nessa publicação, Azevedo atualiza definições teóricas sobre o gênero narrativo, especificamente sobre a crônica e o conto, apontando contemporâneas e negras possibilidades de leitura dessas estruturas que são, na literatura brasileira mais atual, um campo amplo com vastas publicações. Desse modo, esse livro apresenta-se como uma referência salutar e animosa para compor bibliografias teóricas de disciplinas e pesquisas universitárias que tragam como tema a literatura contemporânea brasileira. Sem deixar de servir ao deleite daquela pessoa que queira apenas realizar uma candente leitura.

Por fim, afirmo que concordo sobremaneira com Azevedo quando este, em "Sobre os limites de uma crítica sem limites", último ensaio do Estética e raça, escreve: "E a literatura, já não tenho dúvidas, é nosso carro veloz: por meio dele podemos finalmente ser pessoas, e pertencer a alguém maior que tudo isso que nos rodeia: a nós mesmos." (AZEVEDO, 2021, p. 132-133). Como escreve Glória Anzaldúa em Falando em línguas: uma carta para mulheres escritoras do terceiro mundo, escrever expondo a vida é não esperar a repetição da performance de opressão. Ou ainda copiando a autora: "escrever é confrontar nossos próprios demônios, olhá-los de frente e viver para falar sobre eles" (ANZALDÚA, 2000, p. 234).

Desse modo, Estética e raça é um livro que refresca nossa minguada democracia. Ele é um sinalizador que aponta máscaras de oxigênio. Esse livro diz ao campo da crítica literária brasileira contemporânea: ei, irmã, podemos, sim, respirar melhor. Revirar a literatura negra com honestidade e sério apontamento crítico não é destruir, é construir e colaborar tanto com a própria literatura negra quanto com o cenário da crítica nacional que precisa, sim, dessas alfinetadas, até para obter como respostas novas falas de vida.

Concluo, voltando ao Ensinando a transgredir de bell hooks quando esta afirma: "para curar a cisão entre mente e corpo, nós, povos marginalizados e oprimidos, tentamos resgatar a nós mesmos e às nossas experiências através da língua” (HOOKS, 2017, p. 233). Assim, Estética e raça, de Luiz Maurício Azevedo, é um livro de crítica literária que pode nos auxiliar nesse caminho positivo de transgressão da quietude racista. Silêncio mórbido. Porque se alguns falaram por tantos anos em "paz" é porque tantos outros estavam por tantos anos sendo silenciados. E a alegria de um estado democrático é a constante perturbação do ouvir vozes. 


\section{REFERÊNCIAS}

ANZALDÚA, Glória. Falando em línguas: uma carta para mulheres escritoras do terceiro mundo. Trad. Edna de Marco. Revista Estudos Feministas, v. 8, n. 1, p. 229-236, 2000.

AZEVEDO, Luiz Maurício. Estética e raça: ensaios sobre a literatura negra. Porto Alegre: Sulina, 2021.

CARNEIRO, Suely. Escritos de uma vida. São Paulo: Pólen Livros, 2019.

HOOKS, bell. Ensinando a transgredir: a educação como prática da liberdade. Trad. Marcelo Brandão Cipolla. 2a. ed. São Paulo: Editora WMF Martins Fontes, 2017. 